\title{
Wintering harriers in a rapidly changing landscape in southern Tamil Nadu, India
}

\author{
A. Saravanan, M. B. Prashanth and T. Ganesh* \\ Ashoka Trust for Research in Ecology and the Environment, Royal Enclave, Srirampura, Jakkur Post, Bangaluru 560 064 , India
}

\begin{abstract}
Wintering ecology of many migrant bird species, especially migrant raptors is poorly studied. The semi-arid regions of southern Tamil Nadu (TN), India are a major wintering area and the southern limit for many migrant species. Historically there has been a loss of several grassland species from the area and currently, the natural grasslands are completely transformed. There are no studies on grassland birds in the region, especially on migrant harriers, which are grassland species and show a declining trend in most parts of the country. The present study is an effort to identify harrier roosts and record their numbers at the roost sites, during four winters from 2015 to 2019 in the districts of Tirunelveli and Thoothukudi in TN. Three species of harriers were recorded from 16 roost sites and roost counts at these sites varied from 75 to 2 . The total number of harriers declined over the survey period and this was consistent across sites. Majority of the roosts were on private land and loss of roost sites to various land-use transformations is a major driver of harrier numbers in the area. Innovative approaches to protect and conserve grasslands are the need of the hour for the future of grassland species in the region.
\end{abstract}

Keywords: Grasslands, harriers, migration, roosts, wintering ecology.

MANY migratory birds show population decline across the globe $e^{1,2}$, including those using the Central Asian flyway into India ${ }^{3}$. The declines can be attributed to factors ranging from habitat loss, poaching to climatic changes occurring at the breeding, wintering and migratory stopover points in their annual migration cycle ${ }^{4}$. While considerable attention has been given to understand factors in the breeding areas, such as nest predation and prey availability fluctuations, factors affecting the population in the wintering areas are poorly understood ${ }^{5,6}$. This is particularly critical because migratory birds face various threats in the wintering tropical areas where human population density and high levels of unsustainable development can affect their wintering habitats ${ }^{7-9}$. Species that breed in grasslands and agricultural areas, or those that cross difficult physical barriers such as mountains and deserts are likely to be most affected and least studied ${ }^{10}$. India's

*For correspondence. (e-mail: tganesh@atree.org)
National Action Plan 2018-23 for the conservation of migratory birds highlights the need to 'undertake and publish national inventories of migratory birds'. These include the documentation of stopover and wintering sites of migratory birds, and their population status across habitats such as pastures and farmlands for the conservation of migratory species.

Harriers are diurnal raptors (birds of prey), and six of the 16 species occurring globally are found in India ${ }^{11}$. Five of these migrate during each migratory season to the Indian subcontinent, whereas the pied harrier (Circus macrorus) is reported to breed in India ${ }^{11,12}$. Most harriers have a unique behaviour to congregate in large numbers and roost on the ground in grasslands ${ }^{11}$. Harrier populations migrating into Africa from Europe have shown a consistent decline in their wintering areas ${ }^{13}$, which has been attributed to land-use change in the Sahel region, shifts in prey abundances and change in climate. Sahel is an important wintering area for many migrant birds, including harriers in Africa ${ }^{14,15}$. Amongst the harrier populations, the Montagu's harrier has become rare in southern Africa, the southern limit of the European migrants ${ }^{16}$. Similarly, a recent compilation of historical information on harrier roosts in India $^{17}$ indicates a decline of their numbers across several sites ${ }^{18}$. While the authors do not explicitly state a particular reason for the decline, they allude to multiple factors leading to fall in numbers including possible changes in breeding areas, stopover and wintering areas, and land-use change in and around roost sites. They also stress that areas especially from southern and eastern parts of the harrier's range which are poorly known need to be identified and described to ascertain the changes in harrier population across the country.

Harriers range across the entire length of peninsular India and roosts have been reported from many parts of the country. However, information on harrier roosts located at south of Mysore in Karnataka, especially Tamil Nadu (TN) and Kerala is lacking ${ }^{11,19}$. TN, which was once known for extensive grassland savannahs and harboured unique flora and fauna ${ }^{20,21}$, including the endangered bustards ${ }^{22}$, has no roosting records of harriers. Locally known as mullai, these scrub and grass savannahs are a threatened ecosystem in south TN that exist as small fragmented patches under private or Government ownership (S. Devy, unpublished). Currently, the only grassland-protected area in the region is the scrub-dominated 


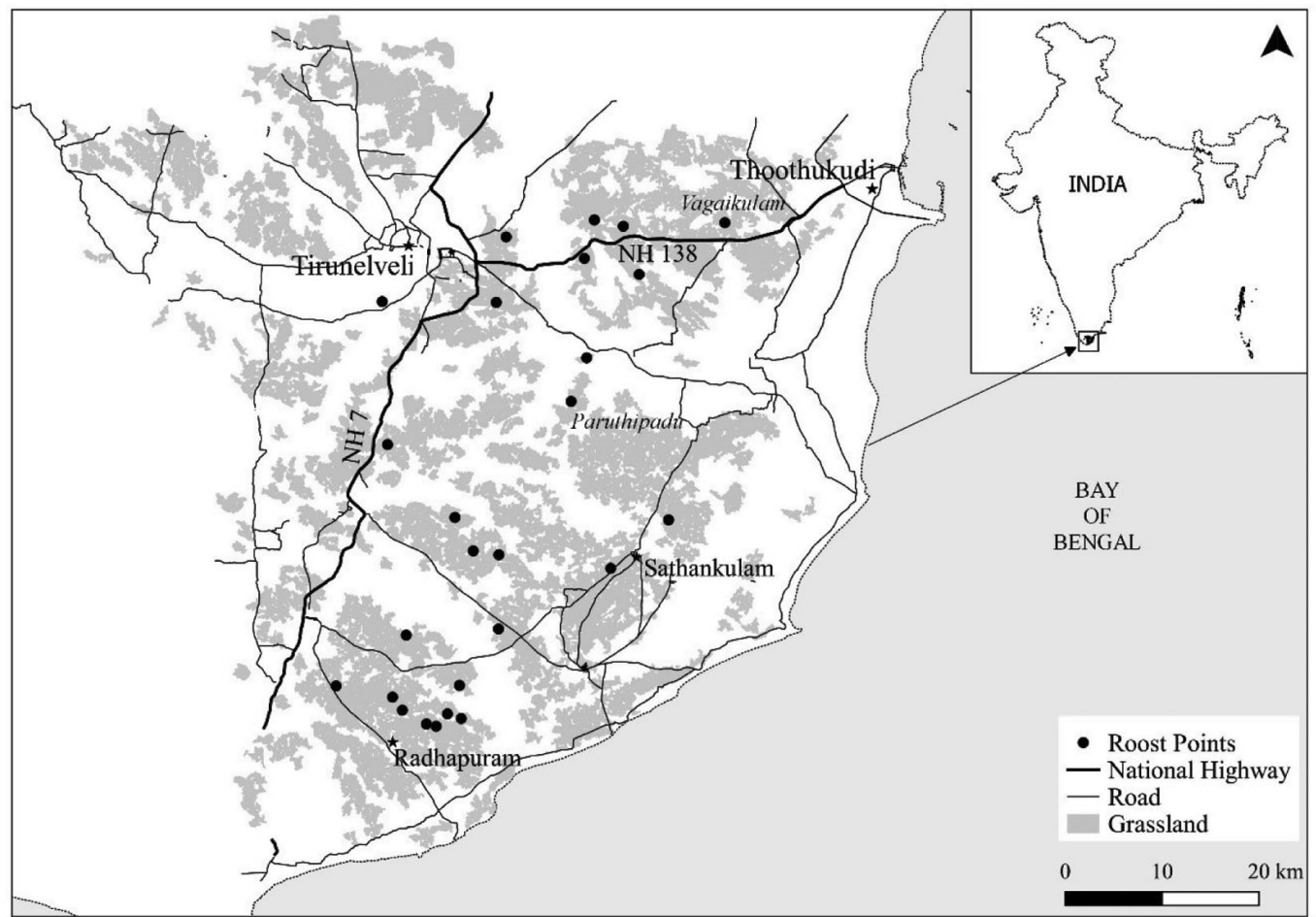

Figure 1. Map of the study area depicting roost locations and major harrier roosts at Paruthipadu and Vagaikulam in Tirunelveli and Thoothukudi districts respectively, Tamil Nadu, India. The grasslands (grey) indicated include agricultural fallow (adapted from S. Devy and A. Samrat, unpublished).

Vallanadu Blackbuck Sanctuary, which is not suitable for most grassland species ${ }^{23,24}$.

Considerable attention has been paid to wetland species and their conservation in India and $\mathrm{TN}$ in particu$\operatorname{lar}^{25-28}$, but open dryland species remain neglected. Considering the shrinkage of grassland habitat in the region and the adverse impacts it would have had on grassland fauna, it is important to develop baseline information of the species present in the area in terms of their occurrence and abundance. In this study we focus on locating harrier roosts, enumerating species and counts of harriers at roosts across four migratory seasons.

\section{Study area}

Tirunelveli and Thoothukudi districts of southern TN are classified as semiarid regions with an average annual rainfall of $801 \mathrm{~mm}$ in the plains, a generally hot and dry climate with annual average temperature of $28.4^{\circ} \mathrm{C}$ (ref. 29). The native vegetation here is classified as Southern Tropical Thorn Forest with Acacia planifrons and Acacia horrid as the dominant species ${ }^{30}$. Currently, however, their distribution is limited in extent due to various anthropogenic pressures, including over-grazing and land-use change. The poor soil and rocky substrate restricts the succession of trees and retains grasslands that sustain over 50 grass species (pers. obs.) dominated by Heterepogon and Aristida species and native reed grass (Ophiuros exaltatus).
The study area spread over about 3500 sq. km was demarcated keeping in view the dryland habitat available to the harriers. Broadly, the area spreads east of the National Highway (NH)-7; south of the Tirunelveli and Thoothukudi highway (NH-138) and north of Radhapuram town in the Tirunelveli and Thoothukudi districts (Figure 1). It comprises a matrix of fallow lands, wetlands paddy and banana fields, grasslands and dry cultivated areas. Paddy and banana are the dominant crops covering a large proportion of the study area. Dry grasslands, fallow lands and croplands that could support harriers are limited and vary with rainfall.

\section{Methods}

\section{Identifying winter roosting grounds}

We obtained grassland map of the area classified using the support vector machine (SVM) algorithm from an earlier study done in 2016. Ground data for the study were collected from 2016-2017 during crop availability (September-December) and when the crop was harvested (February-April) to identify crops and grasslands (A. Samrat et al., unpublished) and images were preprocessed for all land-cover classes. We used Sentinel-1 and Sentinel-2 satellite imagery of $10 \mathrm{~m}$ spatial resolution and developed approximately 485 polygons for the study area. Each polygon covered about 4-16 pixels of the image. The signature was randomly split into $70 \%$ and $30 \%$ 
subset, $70 \%$ was used to train the algorithm and $30 \%$ was used to validate the classification result for both sites. The accuracy obtained for grasslands was $96 \%$. We used Google Earth Engine (GEE) ${ }^{31}$, a freely available cloudcomputing platform for analysis, and open-source QGIS 3.6 (http://qgis.osgeo.org) for analysis and map preparation.

The classified grassland sites were visited by us to identify potential harrier roosts. This was done by visiting the grasslands $2 \mathrm{~h}$ before sunset by two observers to record the roosting activities of harriers. Methods to count harriers during roost were based on previous studies ${ }^{18,32}$. The flying direction of harriers observed a few hours before dusk is a reliable indicator of the presence of roost. Pre-roosting behaviour, where harriers congregate on the ground near a roost and 'milling', a behaviour wherein harriers fly in short circles over the roosting site at dusk, are useful to identify the roosting location. Based on these pointers, roosting sites were identified and coordinates obtained using a GPS gadget. Roosting sites thus identified were shortlisted and monitored across the wintering period (September-April) during the four years. Several roosts sites were ephemeral and found only in certain short periods spanning less than two months in a migratory season. We, therefore, selected sites where roosting occurred through the season for monitoring. This we believe gives a fair account of the trend in bird numbers in the area, though not a population estimate of harrier species.

\section{Roost count}

Harrier roost sites were visited $2 \mathrm{~h}$ before sunset and counts done from a vantage point which provided a clear view in all directions. Species and sex of each harrier flying into the roost site were identified when in clear view. The identified harriers were classified into adult or juvenile categories based on plumage details using $8 \times 40$ binoculars, $60 \times$ zoom camera and detailed field guides $^{33,34}$. Harriers, especially females/juveniles that could not be identified were categorized as 'ringtails'. Each evening, the total counts of harriers were obtained by two methods ${ }^{35}$ : (i) the total count of milling birds counted within a span of 5-10 minutes before roosting, and (ii) in the absence of milling, the total count of harriers that had flown into the roost during the 2 hours at the roost site was considered. Birds once flown into a roost, remain around the location and therefore double counts of the individuals can be avoided. Our comparison of milling and $2 \mathrm{~h}$ counts before roosting over many sites across India, which are mutually independent generally showed a strong agreement.

Monitoring of sites used by harriers was done over four migrating periods from the spring of 2015 to 2018 . In all the years, roost counts were done during three seasons; monsoon (October and November, when the retreating northeast monsoon was active in this region), postmonsoon (winter; December to January) and spring (February to March/April) at each roosting site. A spring count done in the 2014-15 season was also included. Monsoon counts for 2016 could not be done for logistical reasons. Counts were done for a minimum of 2-3 consecutive evenings at a site during each season. Since harriers are known to move between roost sites during the migratory season, an aggregate (average) of roost counts for a season was considered for analysis. Additional information on land use at the roost (viz. protected area, private fallow, grazing land, active farmland), habitat type (viz. open grassland, cleared savannah, untenanted residential plots) grass cover (viz. tall, ungrazed grass or short, grazed grass), presence of predators during the $2 \mathrm{~h}$ of roost counts (viz. fox, birds of prey, dogs) and anthropogenic activities around the roost (viz. piggery, livestock herd movement, land clearing, grass burning) at the time of roosting was recorded. This was not used in the quantitative analysis presented here because of incomplete datasets.

\section{Statistical analysis}

Roost counts were pooled from all the roost sites in the study area to estimate trends. Pooling was done to get a representative sample of harrier numbers over the study area, since harriers can move between sites and a count from a single roost may not be representative of trends over the entire area. Yearwise and season-wise comparison was done using a mean of all roost counts. Trends in roost counts across years and between seasons were tested using Pearson or Spearman correlation, ANOVA or Kruskal-Wallis test depending on the inherent normal or non-normal distribution of data. Pairwise comparisons were done using Tukey's $Q$ test or Mann-Whitney $U$ test $^{31}$.

\section{Results}

\section{Wintering grounds}

We identified 16 roost sites and visited all of them in about $3500 \mathrm{sq}$. $\mathrm{km}$ of sampling area in the two districts. About $70 \%$ of the grassland sites that we visited had roosts (Appendix 1). Roosts were found over a wide area from Radhapuram town $(8.26 \mathrm{~N}, 77.68 \mathrm{E})$ in the south to Vagaikulam village $(8.73 \mathrm{~N}, 78.01 \mathrm{E})$ in the north, and Tharuvai village $(8.66 \mathrm{~N}, 77.69 \mathrm{E})$ in the west to Paruthipadu village $(8.57 \mathrm{~N}, 77.78 \mathrm{E})$ in the east. While most of the small roosts had a maximum of 10-25 harriers, these were ephemeral and were not occupied across the seasons while two sites, viz. Paruthipadu and Vagaikulam that was regularly occupied across seasons and years had 
counts ranging over 50 birds. We pooled all the roost counts to represent changes in roost count over the study area for seasonal and annual changes.

\section{Roost count}

Three species of harriers, viz. Pallid (Circus macrourus, Near Threatened ${ }^{36}$ ), Montagu's harrier (Circus pygargus, Least Concern $^{36}$ ) and Eurasian marsh harrier (Circus aeroginosus, Least Concern ${ }^{36}$ ) were recorded during the four years.

Mean annual counts varied significantly (ANOVA test, $F=20.51 . \mathrm{d} f=3, P<0.001$, Figure 2 ) between years. It was highest in 2015 and significantly lower in 2016 (multiple comparison Tukey's test: $Q=9.305, P=0.0001)$, $2017(Q=6.16, \quad P=0.0001)$ and $2018 \quad(Q=9.975$, $P=0.0001)$. Between the years 2016 and 2018, the roost counts did not decline significantly.

The total counts showed variations across years, but there was an overall significant decrease from 2015 to 18

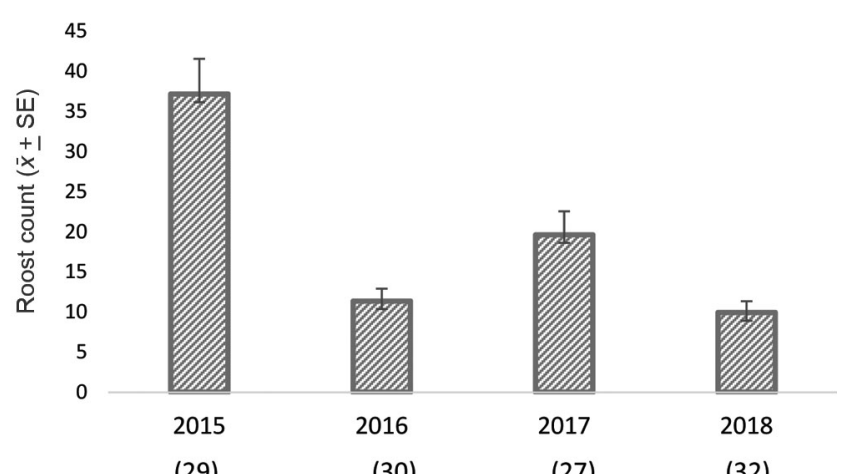

Figure 2. Variation in mean harrier count across four years in southern Tamil Nadu. The number of samples in parenthesis includes all roost counts done across sites and seasons in a year.

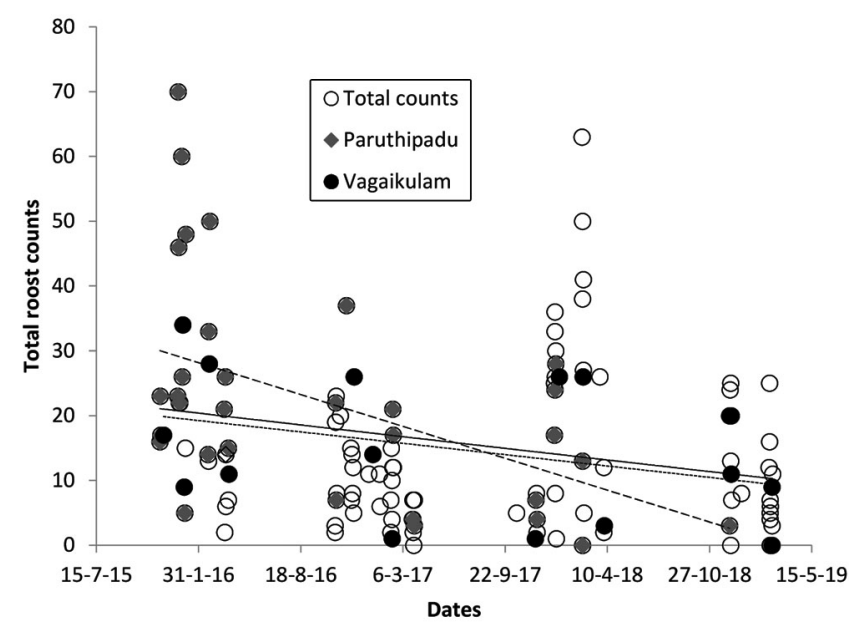

Figure 3. Total counts (solid line) of harriers across all roosts sampled and Paruthipadu (dashed line) and Vagaikulam (dotted line) over four years showing a significant decline.
(Spearman $r_{\mathrm{s}}=-0.29, P=0.0008, n=128$; Figure 3 ). A similar decline in the two major sites, viz. Paruthipadu $\left(r_{\mathrm{s}}=-0.49, P=0.003, n=36\right)$ and Vagaikulam $\left(r_{\mathrm{s}}=\right.$ $-0.530, P=0.02, n=18)$ was also noticed, with a steeper decline in Paruthipadu (Figure 3).

Across seasons winter counts were higher than monsoon counts (Mann-Whitney test, $U=290.5, P=0.0048$ ) and spring counts $(U=565.5, p=0.00012)$. The counts obtained during monsoon and spring did not differ significantly $(U=575.5, P=0.3538)$. Winter counts showed a sharp decline after 2015 and continued to be lower in subsequent years. Spring counts were generally lower than winter counts, except in 2017-18, whereas monsoon counts were low since harriers start arriving in southern TN only by this time of the year (Figure 4).

\section{Species-level variations}

Analysis of species profile of the population of harriers in Tirunelveli and Thoothukudi regions showed that Montagu's male constituted $35 \%$, pallid male $10 \%$, marsh male $2 \%$, marsh female $2 \%$, marsh juvenile $4 \%$ and marsh harriers in total about $8 \%$ of the counts. Estimation of species numbers of ringtails was difficult not only because of plumage similarity between Montagu's and pallid juveniles/females, but also because at dusk, low light and observation distance were not conducive for identification. We, therefore, analysed grey males of both species and Marsh harriers, where sex and age could be more accurately determined to see their trend in counts. While males alone may not completely reflect the dynamics of the population, when we analysed the composition of male harrier data with the total count data, the males comprised $45 \%$ of the total roost counts. Therefore, in terms of population response, analysing male composition is useful to determine the influence of sex of the harriers on the trend in populations.

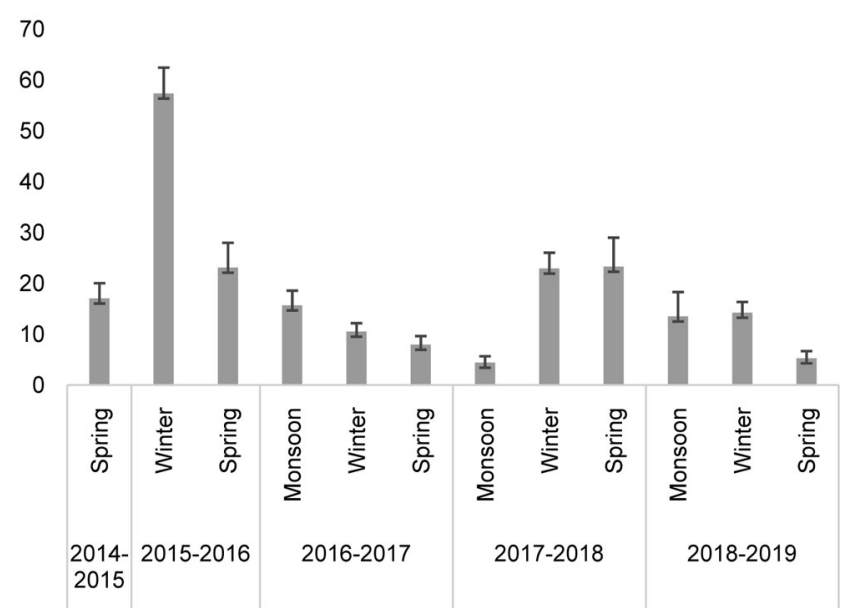

Figure 4. Seasonal variation in mean counts $(x \pm \mathrm{SE})$ of harriers over four years starting with Spring counts for 2014-15. Monsoon counts could not be done for 2015-16. 
Further, Montagu's male count was strongly related to total counts (after excluding Montagu's male count from the total; $r=0.66, P<0.01, n=130)$, whereas the ringtails were not (excluding ringtail counts).

The stacked bar of harrier demography in Figure 5 shows variation across years, seasons and species. Mean percentage of Montagu's harrier males in the counts have increased across the years from 26 in 2015 to 38 in 2019. This occurred in the spring of 2018 and 2019. The other male harriers were much fewer in counts and we could not infer any significant change in their counts, whereas ringtails had decreased from $30 \%$ in 2015 to $22 \%$ in 2019. The proportion of marsh harriers in the counts decreased from $19 \%$ to $5 \%$ across the years.

Species-level variation in counts across the years showed no significant change for Montagu's male harrier ( $r=-0.178, n=119, P=0.056)$, but for Pallid male $(r=-0.46, n=99, P<0.0001)$, marsh male $(r=-0.214$, $n=99, P=0.033)$, marsh female $(r=-0.44, \mathrm{~d} f=98$, $P<0.0001), \quad$ marsh juvenile $(r=-0.31, \quad n=99$, $P<0.001)$ and total marsh harriers $(r=-0.29, n=128$, $P<0.001)$. Ringtails also declined significantly $(r=0.42$, $n=106, P<0.00001)$. In general, for all three species, total counts during 2015 were significantly higher than the rest of the years, and all of them showed a significant negative trend in their counts across the years (Figure 6).

Species-level variations across seasons indicated that Montagu's male harrier did not vary significantly $(H=$ 3.863, $P=0.1418)$, whereas pallid male harriers $(H=13.01, P=0.00075)$, ringtails $(H=17.7, P=0.0001)$ and marsh harriers $(H=10.89, P=0.00183)$ varied
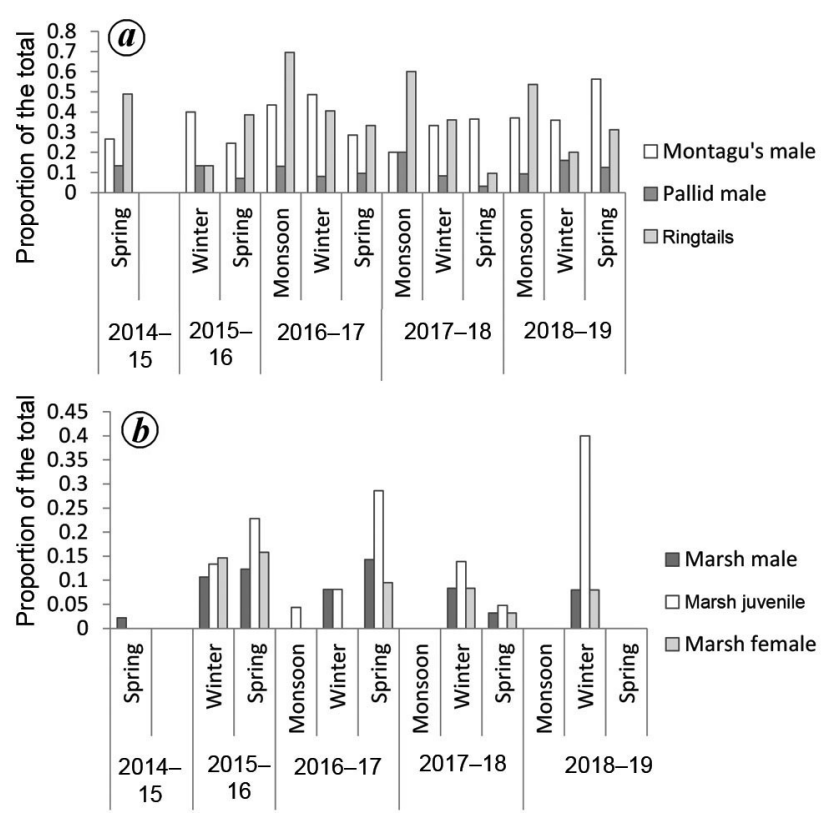

Figure 5. Species, sex and age profile of harriers across seasons and years. (a) Montagu's, pallid and Ringtails and (b) marsh harriers. The values are proportion to total counts for each season. significantly (Figure 7). However, these variations were not similar across species. Montagu's male counts were marginally higher in winter compared to monsoon $(U=$ 381.5, $P=0.0688)$, but did not differ from spring ( $U=864.5, P=0.1283)$, whereas the spring and monsoon counts did not differ either $(U=634.5, P=0.57$; Figure 7). Pallid male counts were high in winter but did not differ significantly from monsoon $(U=494, P=0.7276)$, but were significantly higher than in spring $(U=648$, $P=0.0007$; Figure 7), ringtails peaked in winter and differed from monsoon $(U=353.5, P=0.02903)$ and spring $(U=529, P=0.00005$; Figure 7$)$. Similarly marsh peaked in winter and differed from monsoon $(U=326, P=$ 0.00818 ) and spring ( $U=667.5, P=0.00117$; Figure 7).

The study indicates that harrier numbers have decreased across years for all species, except male Montagu's harrier. Counts of marsh harriers have declined drastically in comparison to other species. Across seasons, the peak in numbers was noticed in winter for most species, but their numbers decreased in spring for male marsh and male pallid harriers; however, male Montagu's harrier counts continued to be high in spring.

\section{Threats}

Of the 16 roosts/sites recorded, 14 were on private land and two on Government land (Appendix 1). Three of these sites have been lost due to land-use change. One of the sites was converted to eucalyptus plantation, another to a windmill farm and the third site was disturbed due to intensive grazing and encroachment. In addition, many of the other roosts are under threat because they lie on private lands and are therefore subject to change in landuse status. Other forms of threat to the habitat are due to the transformation of sites into scrubland by infestation of Prosopis juliflora and colonization by Senna auriculata.

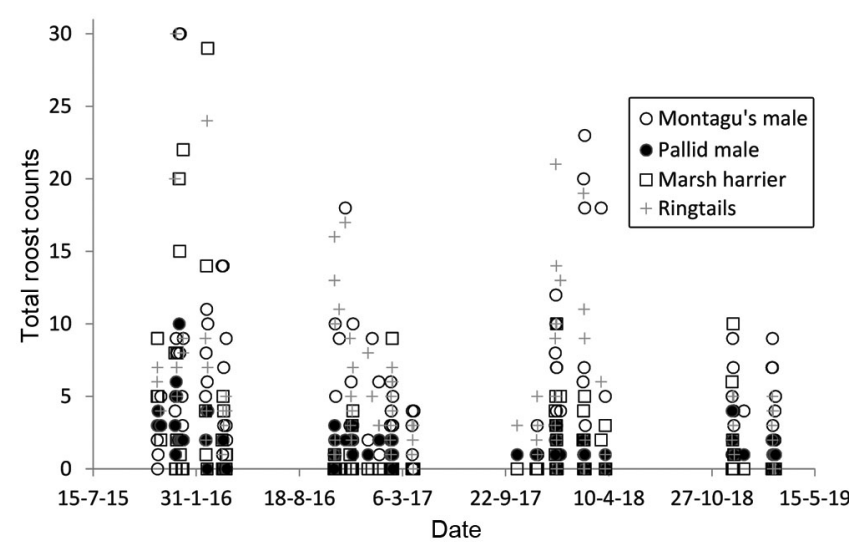

Figure 6. Species-wise counts of harriers over four wintering years. Marsh harriers include males, females and juveniles. Ringtails include unidentified Montagu's and pallid harriers. All species declined significantly. 

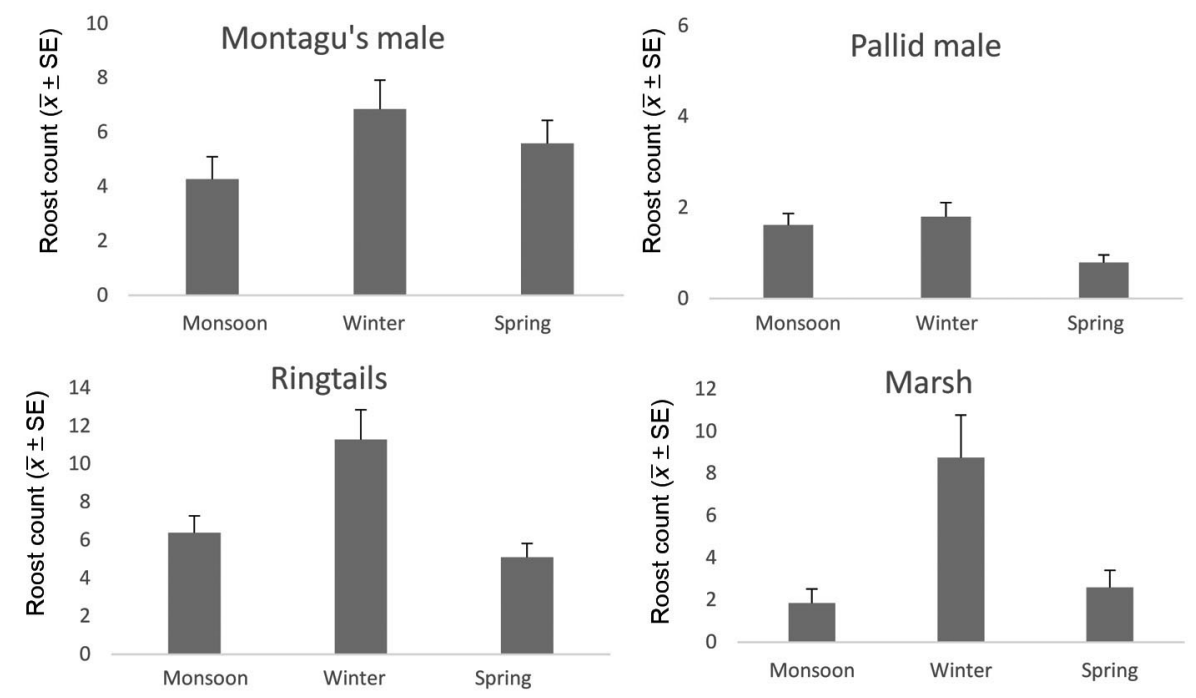

Figure 7. Mean total counts of harrier species across seasons. Marsh harriers include males, females and juveniles. Ringtails include unidentified Montagu's and Pallid harriers.

\section{Discussion}

Five species of harriers are known to occur in $\mathrm{TN}$ of which the three recorded here are the most common. The migration of harriers into southern $\mathrm{TN}$ starts by midSeptember, their numbers peak in December (winter) and the birds leave by end of March or early April. Unlike most other parts of India, southern TN is not affected by the southwest monsoon, whereas the retreating monsoon (northeast winds) brings in most of the precipitation ${ }^{31}$. The period following the northeast monsoon is the most productive with plenty of water, copious growth of grass, abundant prey availability such as grasshoppers, migrating and resident small birds and reptiles, resulting in a high number of harriers.

The number of harriers in the four years was highest in 2015. The roosts such as Paruthipadu in Tirunelveli district recorded a peak of 75 birds. The site further north Vagaikulam - recorded 70 birds. After 2015, there has been a general decline in the number of harriers visiting the sampled roosts (Figure 2). There could be several reasons for such changes and we explore some of them.

\section{Rainfall and drought}

Harrier numbers are often tied to resource availability and in the case of Montagu's harrier, it is the availability of grasshopper prey $^{37}$. Such availability is also linked to rainfall and greenness of the area (measured by NDVI), since high rainfall may result in good grass cover and therefore high number of prey availability ${ }^{38}$. In many places such as Vagaikulam, burning of grass stubble succeeds the grass-harvesting activity, and harriers abandon the sites completely after burning. In 2016, the two districts experienced severe drought and grass productivity was low, and early burning led to a significant drop in harrier numbers (pers. obs.). The general drop in grass productivity appears to drive harrier numbers during the drought year.

\section{Land transformation - loss of roosting habitat}

In the 2017 season even though rainfall was normal, harrier numbers were low across the sites. Montagu's males were higher, but marsh and pallid harrier males were not on par with the counts in 2015. Marsh harriers declined drastically after 2015 and did not increase in 2017, despite normal rainfall and water availability around the surveyed sites. Therefore, recovery of harrier numbers in comparison to the counts in 2015 was not recorded. We conclude that grassland productivity alone may not be influencing the number of harriers visiting the region.

In Vagaikulam, activities such as cattle grazing that prolonged into twilight hours, movement of stray dogs which was persistent and movement of people from the nearby settlements, disturbed the harriers. Unlike other grazing lands, where the grass is grazed by livestock herds, grass in Vagaikulam is manually cut and transported to households leaving little or no cover for the roosting harriers (pers. obs.). In some instances, harriers were tolerant to movement of people and livestock; however, the total loss of grass cover due to cutting or burning forced the harriers to abandon the site much earlier than at the end of spring (pers. obs.).

The highest congregations of marsh harriers were recorded in Paruthipadu, an ideal wintering ground, where more than 50 birds were recorded every evening consistently in the winter of 2015. The area was a matrix of 
large grazing lands (>1000 acres), small wetlands, seasonal streams, short thorny bushes and few palmyra trees. The Paruthipadu grassland is owned by the Nelliappar Temple Board at Tirunelveli. The state government's policy of allotting unproductive land to productive use for revenue generation led the government-owned Tamil Nadu Pulp and Paper Mills to acquire the land at Paruthipadu to raise Eucalyptus plantations by mid-2016. By the winter of 2017, the Eucalyptus saplings were less than $3 \mathrm{ft}$ tall and were used by harriers ( $<10$ birds) for roosting, but from 2018 they stopped roosting or foraging at Paruthipadu. The transformation of this site led to the destruction of a roosting site for harriers in general and especially marsh harriers for which this was an important roosting site, but not a foraging site. However for Montagu's harrier it was loss of both roosting and an important foraging area. The harriers were seen moving into an adjoining tiny fragment of land by the third year which could not support more than 25 birds, in contrast to the 70 roosting harriers at Paruthipadu during the first year (2016). It, therefore, appears that loss of roosting sites due to grassland is responsible for the decrease in Marsh, Montagu's and Pallid harriers in the four years.

Transformation of roost habitat often leads to abandonment of roost site. In Vagaikulam the loss due to drought was temporary, but in Paruthipadu it was a permanent land transformation. Historical data available with one of us (T. Ganesh, pers. commun.) shows sites towards the western side of the districts where harriers were seen earlier, are now transformed and roosting sites have been reclaimed permanently. Such changes repeatedly occur at roosting sites across India and are a major threat outside protected grassland areas in the country ${ }^{17}$. The major harrier roosting grounds across the country such as Velavadar, Tal Chappar, Nannaj and Rollapadu are Protected Areas. The districts of Tirunelveli and Thoothukudi or TN do not hold a grassland protected area. The only sanctuary nearby for blackbuck is a dense scrub habitat not suitable for blackbucks and other grassland birds ${ }^{23,24}$, which puts grassland birds, especially harriers at a greater risk of avoiding their southernmost wintering areas.

\section{Dearth of foraging habitats}

Pallid harrier males were low in numbers all through the four years, probably because of sparse scrub habitat in the area. They have been seen frequently foraging in the native reed grass (Ophiuros exaltatus) areas which are soggy black soil habitats not suitable for agriculture. However, these are small and fragmented patches that are being rapidly transformed into real estate. Over the four years, we also noticed overall drying up of the reed grass patches leading to land transformation. Montagu's harrier showed a preference for open grasslands/fallow areas with short grass. Currently, sites holding short grass are found where real estate activities are temporarily suspended and land cleared of Prosopis juliflora. Though the foraging habitat available for harriers in the area are limited, the land-use change assessed by satellite imagery was not significant across the four years, but showed a dramatic reduction in the grass and scrub habitats over the last 24 years (S. Devy et al., unpublished). Loss of grasslands coupled with variation in rainfall and invasion by $P$. juliflora and other woody species could negatively affect the populations of wintering harriers in the region. Marsh harriers that feed on waterfowl, waders, amphibians and other small birds may not have been affected by lack of prey availability, as these have not declined in the last nine years based on the yearly water bird census done in the area (T.G., unpublished). We, therefore, suspect that the birds have abandoned the area as seen from low encounters on an independent study using road transects (T.G., unpublished) and a few may be using nonoptimal and ephemeral habitats such as dry paddy fields on a temporarily basis (pers. obs.).

\section{Do fall in counts indicate population decline?}

Regular counts of birds and bats at their roosts are considered good indicators of the trend in the population of a species in an area ${ }^{39,40}$. However, species that may have multiple roosts in an area may move between roosts and therefore counts at one roost may not indicate a true decline. It is therefore necessary to include multiple roosts in an area to ascertain population-level changes. Most of the harrier species in this study ranged between 5 and $10 \mathrm{~km}$ per day from their roost site and often spent the entire winter in one or few roost sites within this $5-10 \mathrm{~km}$ range, provided the roost conditions did not change dramatically (T.G., unpublished). However, individual birds would move between roosts in the area and therefore any trend in the population of harriers would need a sampling of multiple roosts in the area. In this study, we sampled most of the recorded roosts in the area and recorded count at two major roosts, both of which showed a declining trend. Our spatial analysis of grasslands did not reveal any large grasslands/fallow lands ( $>10 \mathrm{sq} . \mathrm{km})$ that could harbour large roosts of harriers (above 75-100 harriers recorded in 2015). We, therefore, conclude that the declining trend could be an indicator of the actual decline in harrier occurrence across the sampled area.

Pooling juvenile and female Montagu's and Pallid harriers sets a limitation in inferring population trends at the species level. Sex ratio in harriers is not stable across years ${ }^{41}$, which creates an additional dimension in assessing population regulation at the species level. Improvement in harrier identification is required by using state of the tools, and such a limitation was countered by counting and identifying the birds as they arrived at the roost 
Appendix 1. Roosting locations in Tirunelveli (TVL) and Thoothukudi (TK) districts of Tamil Nadu (Yes, Present; No, Absent). Abandoned real estate - where land has been cleared over the last five years and no construction has taken place leading to copious grass cover. Agricultural fallow - sites where agriculture was done in the past (more than one year ago) and is not currently in use. Grazing pressure was noted based on the number of livestock seen in the area

\begin{tabular}{|c|c|c|c|c|c|}
\hline Roost site & $\begin{array}{l}\text { Abandoned } \\
\text { real estate }\end{array}$ & $\begin{array}{l}\text { Agricultural } \\
\text { fallow }\end{array}$ & $\begin{array}{c}\text { Roost } \\
\text { abandoned }\end{array}$ & $\begin{array}{c}\text { Overgrazing } \\
\text { pressure }\end{array}$ & Changes over four wintering periods \\
\hline Vagaikulam (TK) & No & Yes & No & Yes & Increased grazing and human presence \\
\hline Theivaseyalpuram (TK) & No & Yes & No & Yes & Turning woody \\
\hline Panayankulam (TVL) & Yes & Yes & No & Yes & Cleared the grass, real estate \\
\hline Sivanthipatti (TVL) & No & No & No & Yes & Real estate, turning woody \\
\hline Tharuvai (TVL) & Yes & No & No & Yes & Road networks, real estate \\
\hline Paruthipadu (Government land; TVL) & No & No & Yes & Yes & Converted to plantation \\
\hline Perumal Nagar (TVL) & Yes & Yes & No & Yes & Turning woody \\
\hline Koonthakulam (TVL) & No & No & No & Yes & Agriculture, roost ephemeral \\
\hline Sriranganathapuram (TVL) & Yes & Yes & No & Yes & Turning woody \\
\hline North Vijayanarayanam (TVL) & No & No & No & No & Turning woody \\
\hline Nellaiyappapuram (TVL) & Yes & Yes & Yes & Yes & Increased grazing and human presence \\
\hline Kannakulam (Government land; TVL) & No & No & Yes & Yes & Wind mill \\
\hline Kottaikarunkulam South (TVL) & No & Yes & No & Yes & Real estate, turning woody \\
\hline Kottaikarunkulam North (TVL) & No & Yes & No & Yes & Quarry widening \\
\hline Ilayanainarkulam (TVL) & No & Yes & No & No & Turning woody \\
\hline Samugarengapuram South (TVL) & No & Yes & No & No & Quarry widening, constructed buildings \\
\hline
\end{tabular}

and not while making in poor light. This provides some clue to the ratio of male: female : juveniles in the populations, but without a close-up view identification of most birds is difficult and so the ratios of composition are not presented here. Moreover, multiple moving birds at a roost will offer less chances of identification in comparison to identifying solitary foraging harriers. However, with high-zoom cameras to take good-close up photographs of birds in the evening light and greater familiarity with individual behaviour, it would be possible to identify these birds more reliably in the future.

As mentioned earlier, the two study districts in TN known for their savanna grasslands and fauna in the past are devoid of any grassland reserves today. The existing government policies do not offer protection to grazing lands, which have enabled the transformation of these lands. In such a situation, stakeholders, particularly local NGOs catering to wildlife conservation, pastoralists and the interests of farmers may play a critical role in the conservation of grazing lands, and the characteristic flora and fauna. A policy initiative to involve local communities, administrative bodies and stakeholders to harbour the existing grazing lands and further declare them as community reserves might help in conserving grassland biodiversity in the study area.

\section{Conclusion}

The study provides the first ever baseline information of a raptor species population from the large unprotected plains of south Tamil Nadu. This intensive field based study has shown a general decline in counts of harriers over the last four years. This decline may be due to the rapid transformation of the grasslands and consequent loss of roost sites due to various developmental activities in the area. The southernmost grassland habitat, often neglected in conservation discourses of the country, is important for many migrant birds and innovative approaches by the state are needed to conserve them. The study focused largely on male birds of Pallid and Montagu's harrier and we emphasize the need to look at age and sex of the species with use of modern photography and experienced observers to better understand demographic changes in populations.

1. Ruegg, K. C. et al., Mapping migration in a songbird using high-resolution genetic markers. Mol. Ecol., 2014, 23(23), 57265739.

2. Thiollay, J. M., The decline of raptors in West Africa: long-term assessment and the role of protected areas. Ibis, 2006, 148, 240254.

3. Mundkur, T., Conserving birds and their habitats along the Central Asian Flyway, Hornbill, 2017, 4-11.

4. Rappole, J. H. and McDonald, M. V., Cause and effect in population declines of migratory birds. Auk, 1994, 111(3), 652660.

5. Somveille, M., Rodrigues, A. S. and Manica, A., Why do birds migrate? A macroecological perspective. Global Ecol. Biogeogr., 2015, 24(6), 664-674.

6. Sillett, T. S. and Holmes, R. T., Variation in survivorship of a migratory songbird throughout its annual cycle. J. Anim. Ecol., 2002, 71(2), 296-308.

7. Loss, S. R., Will, T. and Marra, P. P., Refining estimates of bird collision and electrocution mortality at power lines in the United States. PLoS ONE, 2014, 9(7), p.e101565; doi:10.1371/ journal.pone.0101565.

8. Manville, A. M., Impacts to birds and bats due to collisions and electrocutions from some tall structures in the United States: wires, towers, turbines, and solar arrays - state-of-the-art in addressing the problems. In Problematic Wildlife: A CrossDisciplinary Approach, Springer, Switzerland, 2016, 1st edn, pp. 415-442. 
9. Beauchamp, G., Long-distance migrating species of birds travel in larger groups. Biol. Lett., 2011, 7(5), 692-694.

10. Anon., India's national action plan for migratory birds and their habitats along the Central Asian Flyway, 2018; http://envfor. nic.in/sites/default/files/press-releases/CAF_NAP_Final\%20 with\%20CL.pdf (accessed in January 2019).

11. Naoroji, R., Birds of Prey of the Indian Subcontinent, Christopher Helm, 2006.

12. Narayan, G. and Rosalind, L., New record of the pied harrier Circus melanoleucos (Pennant) breeding in Assam Duars, with a brief review of its distribution. J. Bombay Nat. Hist., Soc., 1991, 88(1), $30-34$.

13. Thiollay, J. M., Severe decline of large birds in the Northern Sahel of West Africa: a long-term assessment. Bird Conserv. Int., 2006, 16, 353-365.

14. Trierweiler, C. and Koks, B. J., Living on the Edge: Wetlands and Birds in a Changing Sahel (eds Zwarts, L. et al.), KNVV Publishing, Zeist, The Netherlands, 2009, pp. 312-327.

15. Zwarts, L., Bijlsma, R. G., Van der Kamp, J. and Wymenga, E., Living on the Edge: Wetlands and Birds in a Changing Sahel, KNVV Publishing, Zeist, The Netherlands, 2009.

16. Harrison, J. A. and Cherry, M., The atlas of southern African birds, Johannesburg: BirdLife SA, 1997, 1, 708-709.

17. Ganesh, T. and Prashanth, M. B., A first compilation of harrier roost counts from India suggests population declines of wintering birds over 30 years. Ardea, 2018, 106(1), 19-30.

18. Ganesh, T. and Prashanth. M. B., How the decline in India's harrier population hurts its farmers, 2017; https://scroll.in/article/ 830513/indias-depleting-grasslands-are-leading-to-a-drop-in-thepopulation-of-birds-that-aid-crop-growth

19. Thejaswi, S., Shivaprakash, A. and Mohan Kumar, M., A note on harrier roosts in the Mysore area. J. Bombay Nat. Hist. Soc., 2004, 101(3), 450-451.

20. Johnsingh, A. J. T., Field days: a naturalist's journey through South and Southeast Asia, Universities Press, Hyderabad, 2006.

21. Rangarajan, M. and Sivaramakrishnan, K., India's Environmental History: From Ancient Times to the Colonial Period, Permanent Black, Ranikhet, 2011, pp. 1-34.

22. Rahmani, A. R. and Manakadan, R., The Great Indian Bustard and Lesser Florican in Tamil Nadu, Blackbuck, 1988, 4(3), 3-8.

23. Prashanth, M. B., Saravanan, A., Mathivanan, M. and Ganesh, T., Conservation of a fragmented population of blackbuck (Antilope cervicapra). Curr. Sci., 2016, 111(3), 543-549.

24. Prashanth, M. B., Saravanan, A., Mathivanan, M., Shenbagamorthy, S. and Ganesh, T., Distribution patterns and habitat requirements of blackbuck in Vallanadu Blackbuck Sanctuary: implications for conservation and management. Indian For., 2014, 140(10), 1005-1013.

25. Vijayan, V. S., Inland wetlands of India: conservation priorities. Salim Ali Centre for Ornithology and Natural History, Coimbatore, 2004.

26. Subramanya, S., Heronries of Tamil Nadu. Indian Birds, 2005, 1(6), 126-140.

27. Abhisheka, K., Patrick David, J., Prashanth, M. B., Seshadri, K. S. and Ganesh, T., First detailed survey of waterbirds in Tirunelveli and Tuticorin districts, Tamil Nadu, India. J. Threat. Taxa, 2013, 5(12), 4641-4652.

28. Prashanth, M. B., Seshadri, K. S., Mathivannan, M. and Ganesh, T., The good and bad of drought to waterbirds in a river basin. In
Proceedings of the International Conference on Indian Ornithology, SACON, 2013.

29. India Meterological Department, 2015-2019; http://www.imd. gov.in

30. Champion, S. H. and Seth, S. K., A Revised Survey of the Forest Types of India, Government. of India Press, New Delhi, 1968.

31. Gorelick, N., Google Earth Engine, In EGU General Assembly Conference Abst., 2013, vol. 15, p. 11997.

32. Ganesh, T. and Kanniah, P., Roost counts of harriers Circus spanning seven winters in Andhra Pradesh, India. Forktail, 2000, 16, $1-4$.

33. Forsman, D., The Raptors of Europe and the Middle East: A Handbook of Field Identification, T\&AD Poyser, London, UK, 1999.

34. Grimmett, R., Inskipp, C. and Inskipp, T., Birds of the Indian Subcontinent: India, Pakistan, Sri Lanka, Nepal, Bhutan, Bangladesh and the Maldives, Bloomsbury Publishing, New Delhi, 2013; https://www.bloomsbury.com/in/birds-of-the-indian-subcontinent9788193315095/

35. Sutherland, W. J. (ed.), Ecological Census Techniques: A Handbook, Cambridge University Press, Cambridge, UK, 2006; http://www.ecolab.bas.bg/main/Members/snikolov/Sutherland 2006_Ecological_Census_Techniques.pdf

36. IUCN, The IUCN Red List of Threatened Species. Version 20202, 2020; https://www.iucnredlist.org (accessed on 3 December 2020).

37. Trierweiler, C. et al., A Palaearctic migratory raptor species tracks shifting prey availability within its wintering range in the Sahel. J. Anim. Ecol., 2013, 82(1), 107-120; https://doi.org/(...)652656.2012.02036.x.

38. Thorup, K. et al., Resource tracking within and across continents in long-distance bird migrants. Sci. Adv., 2017, 3(1), e1601360.

39. Casagrande, D. G. and Beissinger, S. R., Evaluation of four methods for estimating parrot population size. Condor, 1997, 99(2), 445-457.

40. Barlow, K. E. et al., Citizen science reveals trends in bat populations: the National Bat Monitoring Programme in Great Britain. Biol. Conserv., 2015, 182, 14-26.

41. Simmons, R., Harriers of the World. Their Behaviour and Ecology, Oxford University Press, New York, USA, 2000, p. 368.

ACKNOWLEDGEMENTS. We thank the Department of Science and Technology, Government of India for funds and Tamil Nadu Forest Department for the permission to conduct this study. This work was also catalysed and supported by the Office of Principal Scientific Adviser to the Government of India. We also thank the three anonymous reviewers and Dr Soubadra Devy (ATREE) for sharing unpublished information on the grasslands of the landscape; Abhishek Samrat (ATREE) for help with the maps and for accompanying us during field visits; S. Tamizazhagan (ATREE) and S. Thalavai Pandi (ATREE) for assistance during field work, Dr Rajasekhar Rajamanickam for cover picture and Mr M. Senthil (MG organic Farm, Moolakaraipatti) for providing accommodation.

Received 4 April 2019; revised accepted 14 October 2020

doi: $10.18520 / \mathrm{cs} / \mathrm{v} 120 / \mathrm{i} 3 / 553-561$ 